\title{
Incidence of local recurrence and second primary tumors in resected stage I lung cancer
}

From 1973 to 1985,598 patients underwent resection for stage I non-small-cell lung cancer. There were $291 \mathrm{~T} 1$ lesions and $307 \mathrm{~T} 2$ lesions. The male/female ratio was 1.9:1. The histologic type was squamous carcinoma in 233 and nonsquamous carcinoma in 365 . Lobectomy was performed in 511 patients $(85 \%)$, pneumonectomy in $25(4 \%)$, and wedge resection or segmentectomy in $62(11 \%)$. A mediastinal lymph node dissection was carried out in 560 patients $(94 \%)$ and no lymph node dissection in $38(6 \%)$. Fourteen postoperative deaths occurred $(2.3 \%)$. Ninety-nine percent of the patients were observed for a minimum of 5 years or until death with an overall median follow-up of 91 months. The overall 5- and 10-year survivals (Kaplan-Meier) were 75\% and 67\%, respectively. Survival in patients with T1 N0 tumors was $82 \%$ at 5 years and $74 \%$ at 10 years compared with $68 \%$ at 5 years and $60 \%$ at 10 years for patients with T2 tumors $(p<0.0004)$. The overall incidence of recurrence was $27 \%$ (local or regional $7 \%$, systemic $20 \%$ ) and was not influenced by histologic type. Second primary cancers developed in 206 patients $(34 \%)$. Of these, $70(34 \%)$ were second primary lung cancers. Despite complete resection, 31 of 62 patients $(50 \%)$ who had wedge resection or segmentectomy had recurrence. Five- and 10-year survivals after wedge resection or segmentectomy were $59 \%$ and $35 \%$, respectively, significantly less than survivals of those undergoing lobectomy (5 years, 77\%; 10 years, $70 \%$ ). The 5- and 10-year survivals in the 38 patients who had no lymph node dissection were reduced to $59 \%$ and $32 \%$, respectively. Apart from the favorable prognosis observed in this group of patients, three facts emerge as significant: (1) Systematic lymph node dissection is necessary to ensure that the disease is accurately staged; (2) lesser resections (wedge/segment) result in high recurrence rates and reduced survival regardless of histologic type; and (3) second primary lung cancers are prevalent in long-term survivors. (J THORAC CARDIOVASC SURG 1995;109:120-9)

Nael Martini, MD, ${ }^{a}$ Manjit S. Bains, MD, ${ }^{\text {a }}$ Michael E. Burt, $\mathrm{MD}, \mathrm{PhD},{ }^{\mathrm{a}}$ Maureen F. Zakowski, $\mathrm{MD}^{\mathrm{b}}$ (by invitation), Patricia McCormack, MD, ${ }^{\mathrm{a}}$ Valerie W. Rusch, MD, ${ }^{a}$ and Robert J. Ginsberg, MD, ${ }^{a}$ New York, N.Y.

S tage I non-small-cell lung cancer represents early cancer and is best treated by surgery whenever possible. Despite the expectation of long-term survival after resection without adjuvant therapy, recurrences or new cancers develop in a third of the patients, ${ }^{1-3}$ emphasizing the need for continued surveillance. The frequency of recurrences and new

From the Departments of Surgery ${ }^{\mathrm{a}}$ and Pathology, ${ }^{\mathrm{b}}$ Memorial Sloan-Kettering Cancer Center and Cornell University Medical College, New York, N.Y.

Read at the Seventy-fourth Annual Meeting of The American Association for Thoracic Surgery, New York, N.Y., April 24-27, 1994.

Address for reprints: N. Martini, MD, 1275 York Ave., New York, NY 10021.

Copyright $(\mathcal{C} 1995$ by Mosby-Year Book, Inc.

$0022-5223 / 95 \$ 3.00+0 \quad \mathbf{1 2 / 6 / 6 0 1 3 9}$ primary cancers varies from one report to another. Because of the large number of patients with lung cancer treated by us at various stages of their disease, we have analyzed our experience with the surgical treatment of stage I tumors, focusing on tumor size, histologic type, extent of resection, and the incidence of recurrence and new cancers observed in the course of their follow-up. We here present our results.

\section{Patients and methods}

From 1973 to 1985 inclusive, 3145 patients with nonsmall-cell lung cancer were treated primarily at Memorial Hospital. Those treated elsewhere initially and then referred to us with recurrence or metastases have been excluded. During that period, 598 patients underwent resection for pathologic stage I disease (T1 N0 M0 and T2 N0 M0). 
Table I. Criteria for diagnosis of multiple lung cancers

\author{
Metachronous tumors \\ I. Histologic type different \\ II. Histologic type the same, if: \\ A. Free interval between cancers is at least 2 years or \\ B. Origin from carcinoma in situ or \\ C. Second cancer in different lobe or lung, but: \\ 1. No carcinoma in lymphatics common to both \\ 2. No extrapulmonary metastases at time of diagnosis \\ Synchronous tumors \\ I. Tumors physically distinct and separate \\ II. Histologic type \\ A. Different \\ B. Same, but in different segment, lobe, or lung, if: \\ 1. Origin from carcinoma in situ \\ 2. No carcinoma in lymphatics common to both \\ 3. No extrapulmonary metastases at time of diagnosis
}

At thoracotomy the extent of intrathoracic disease was carefully assessed with particular reference to regional lymph nodes ( $\mathrm{N} 1$ or $\mathrm{N} 2$ ). A complete resection of all disease in the lung was carried out, as well as a mediastinal lymph node dissection in the majority of patients. Postoperative pathologic staging was done after the resected specimen was reviewed histologically and all regional nodes were assessed. Histologic type, tumor location, tumor size in centimeters, histologic clearance at bronchial and vascular resection margins, and visceral pleural involvement were recorded. The surgical and pathologic reports of all patients were carefully reviewed to ensure that the resection was complete, that no residual tumor, gross or microscopic, was left behind, and that no involved regional nodes ( $\mathrm{N} 1$ and N2) were present. Tumor grading, vascular or lymphatic invasion within lung parenchyma, and flow cytometry were not routinely reported. However, several recent reports have suggested that these parameters adversely affect overall survival. ${ }^{4-9}$ For that reason, 200 specimens were randomly selected for blinded review by one of us (M.F.Z.). The tumors were categorized into well-differentiated, moderately differentiated, and poorly differentiated grades.

We defined local recurrence as evidence of tumor within the same lung or at the bronchial stump, regional recurrence as clinically or radiologically manifest disease in the mediastinum or in supraclavicular nodes, and distant recurrence as disease in the contralateral lung or outside the hemithorax. The criteria used for the diagnosis of multiple lung cancers are shown in Table I.

Survival was calculated by the Kaplan-Meier method, including postoperative deaths and all lung cancer-related deaths. Differences in survival were determined by the log-rank test and differences in frequency data by the $\chi^{2}$ test. Significance was defined as $p \leq 0.05$.

The patients comprised 392 men and 206 women, a ratio of 1.9:1. The age range was 19 to 86 years with a median age of 62 years. The tumor was located in the right lung in 359 patients $(60 \%)$ and in the left lung in 239 (40\%) (Table II). Thirteen of the tumors were in the main
Table II. Location of the primary tumor

\begin{tabular}{lcc}
\hline & Right lung & Left lung \\
\hline Upper lobe & 238 & 162 \\
Middle lobe & 36 & - \\
Lower lobe & 77 & 69 \\
Main bronchus & 5 & 8 \\
Intermediate bronchus & $\frac{3}{359}$ & $\overline{239}$ \\
Total & & \\
\hline
\end{tabular}

Table III. Extent of pulmonary resection

\begin{tabular}{ccc} 
Resection & \multicolumn{2}{c}{$\begin{array}{c}\text { No. of } \\
\text { patients }\end{array}$} \\
\hline Lobectomy & 511 \\
Lobe only & $445^{*}$ & \\
Bilobes & 60 & \\
Lobe + sleeve & 6 & 25 \\
Pneumonectomy & & $49^{*}$ \\
Wedge resection & & $13^{*}$ \\
Segmentectomy & & \\
\hline
\end{tabular}

${ }^{*}$ No mediastinal lymph node dissection was carried out in 9 lobectomies, 26 wedge resections, and 3 segmentectomies.

bronchus beyond $2 \mathrm{~cm}$ of the carina, $400(67 \%)$ in the upper lobe, 146 in the lower lobe, and 36 in the right middle lobe.

The histologic type was squamous carcinoma in 233 patients (39\%) and nonsquamous carcinoma in $365(61 \%)$ (adenocarcinoma, 253; bronchoalveolar carcinoma, 98; large-cell carcinoma, 14).

There were 291 T1 N0 M0 tumors (49\%) and 307 $(51 \%)$ T2 N0 M0 tumors (51\%). Sixty patients had tumors $1 \mathrm{~cm}$ or smaller, of which 20 were radiographically occult tumor (TX lesions), 217 had tumors $2 \mathrm{~cm}$ or smaller, 351, $3 \mathrm{~cm}$ or smaller, 164, larger than $3 \mathrm{~cm}$ to $5 \mathrm{~cm}$, and 83 , greater than $5 \mathrm{~cm}$. The visceral pleura was involved in 113 patients, 51 of whom had tumors $3 \mathrm{~cm}$ or smaller.

Lobectomy was performed in 511 patients (85\%), pneumonectomy in $25(4 \%)$, and wedge resection or segmentectomy in $62(11 \%)$ (Table III). Of the latter group, 55 of 62 patients $(89 \%)$ had T1 tumors. A mediastinal lymph node dissection was carried out in 560 patients $(94 \%)$ and lymph node sampling and no formal dissection in 38 (6\%).

\section{Results}

Ninety-nine percent of the patients were observed for a minimum of 5 years or until death (median follow-up: 91 months). Only seven patients alive and well and one patient alive with disease were observed for less than 5 years from treatment. Fourteen postoperative deaths occurred, an incidence of $2.3 \%$, all in patients with lobectomy. The causes of death included myocardial infarction in six, respiratory failure or pneumonia in six, renal failure in one, 


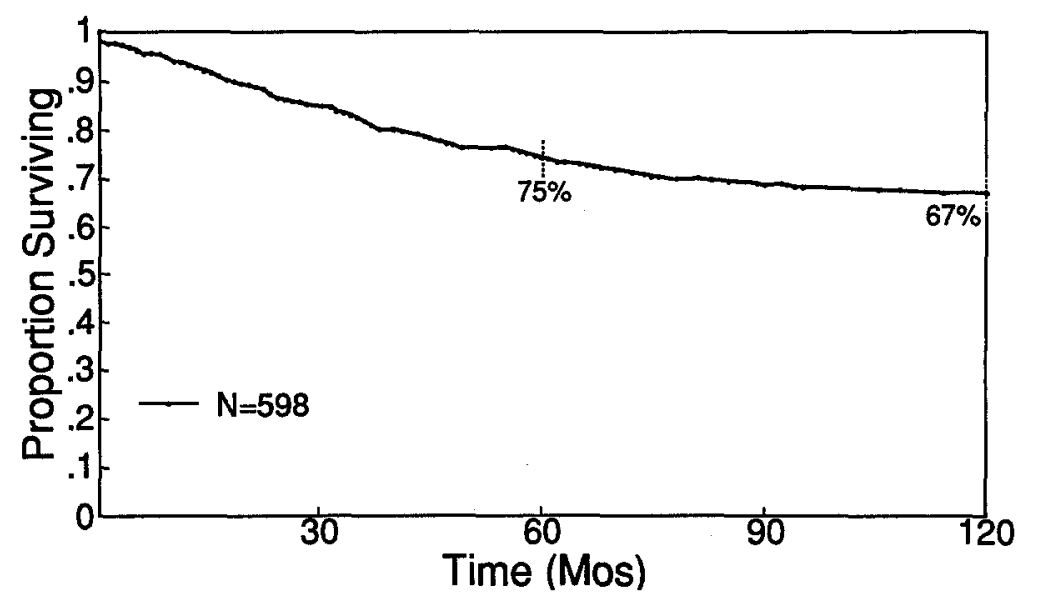

Fig. 1. Overall survival after resection of stage I non-small-cell lung cancer.

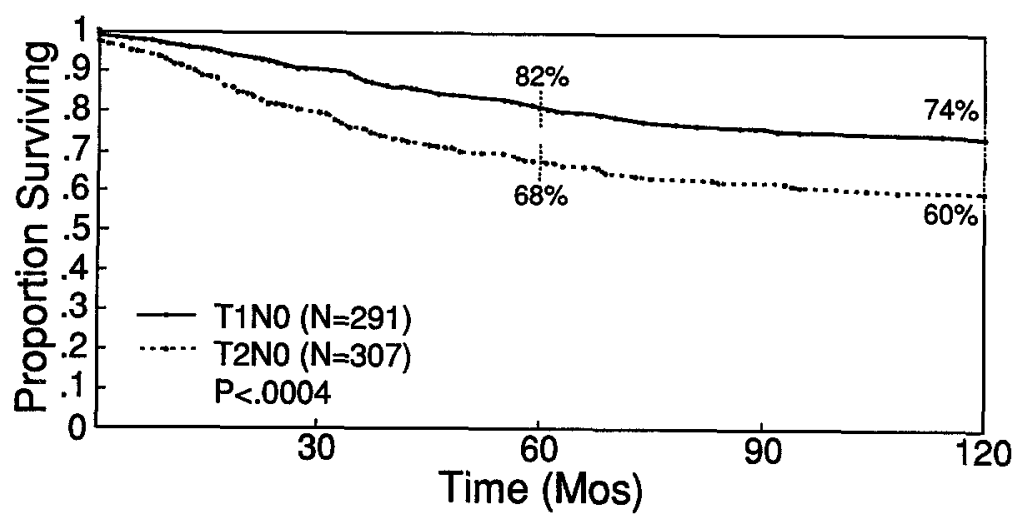

Fig. 2. Survival by $\mathrm{T}$ factor in resected stage I lung cancer.

and spontaneous esophageal perforation with secondary mediastinitis in one.

Twenty radiologically occult lung cancers were detected on sputum cytology, localized by bronchoscopy, and subsequently resected. Of these, 19 were squamous cell cancers and one was a bronchoalveolar carcinoma. The patient with bronchoalveolar carcinoma died of recurrence 2 years later. One patient with squamous cancer died of liver metastases $6 \frac{1}{2}$ years after initial treatment. The remainder are either alive and free of disease or have died of unrelated causes. The 5- and 10-year survivals of this small group of patients were $95 \%$ and $87 \%$, respectively.

The overall 5- and 10-year survivals were $75 \%$ and $67 \%$ (Fig. 1). Survival of patients with T1 tumors was $82 \%$ at 5 years and $74 \%$ at 10 years, compared with $68 \%$ at 5 years and $60 \%$ at 10 years for those with T2 tumors $(p<0.0004)$ (Fig. 2). Because the exact diameter of each resected tumor was recorded, each subset (T1 and T2) was analyzed further by tumor size in centimeters. We found that tumor size in centimeters influenced survival with significant $p$ values between the ranges shown in Fig. 3 . Differences in survival were not significant between (1) patients with tumors $2 \mathrm{~cm}$ or less in diameter and those with tumors $3 \mathrm{~cm}$ or less in diameter $(p=0.63)$, (2) patients with tumors $1 \mathrm{~cm}$ or less in diameter and those with tumors $2 \mathrm{~cm}$ or less in diameter $(p=0.24)$, and (3) patients with tumors 1 to $2 \mathrm{~cm}$ in diameter versus 2 to $3 \mathrm{~cm}$ in diameter $(p=0.71)$.

The extent of pulmonary resection influenced survival. Among 536 patients who had a lobectomy or pneumonectomy, the 5- and 10-year survivals were $77 \%$ and $70 \%$, respectively, compared with $59 \%$ and $35 \%$ in the 62 patients who had lesser resections $(p=0.026)$.

The retrospective grading of the 200 randomly selected cases did not demonstrate any survival advantage by grade in these patients. 


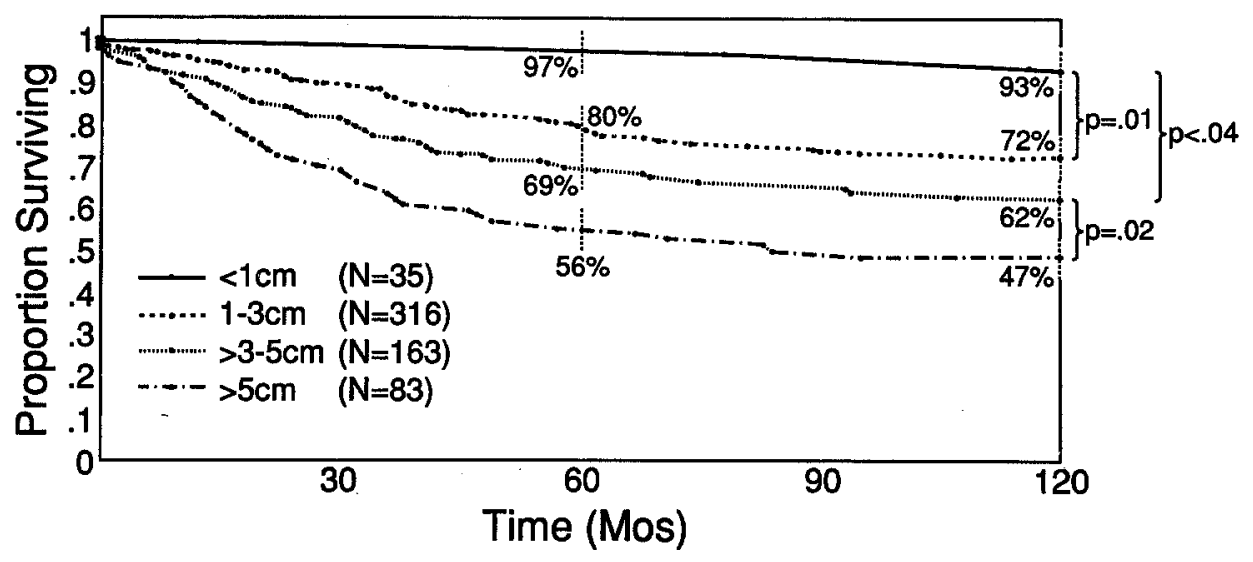

Fig. 3. Survival by tumor size in centimeters.

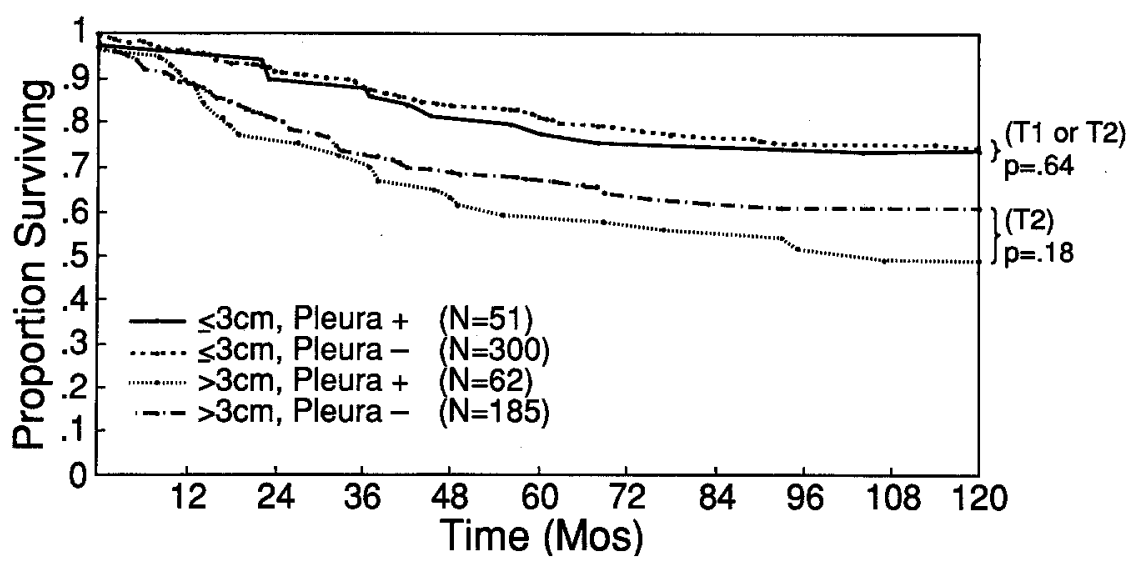

Fig. 4. Survival by visceral pleural invasion and tumor size.

Visceral pleural involvement did not affect overall survival $(p=0.06)$ but was a contributing adverse factor in patients with large tumors (Fig. 4).

No difference in overall survival was identified in patients who had squamous cell tumors compared with those who had nonsquamous cancers (Fig. 5). However, among patients with nonsquamous cancers, those with $\mathrm{T} 1$ lesions did better than those with T2 tumors $(p=0.0008)$ (Fig. 6). This survival difference was not apparent in patients with squamous cancers $(p=0.12)$.

Survival was also calculated excluding wedge resections and segmentectomies and was $85 \%$ at 5 years for patients with T1 tumors and $69 \%$ for those with $\mathrm{T} 2$ tumors, with an overall 5-year survival of $77 \%$.

Recurrence. During the course of follow-up, recurrence developed in 159 of 598 patients (27\%). Of these, $141(89 \%)$ died of their disease, 7 are alive with disease $(4 \%)$, and $11(7 \%)$ have had successful control of their recurrence; 9 of the 11 are still alive and well and 2 have died of unrelated causes.

In $60 \%$ of the patients with recurrent disease, the recurrence developed within the first 2 years after the operation. Although the incidence of recurrence diminished with time, $9 \%$ of patients had recurrence 5 or more years after their initial surgical treatment (Table IV). The longest free interval in our series was 12 years in a patient with a solitary brain lesion that was successfully removed.

The overall incidence of recurrence was $27 \%$ and was not influenced by histologic type. The first sites of recurrence, for all patients and according to histologic type, are shown in Table V. The first sites of recurrences in the overall group of patients were mostly distant (local $20 \%$, regional $8 \%$, and distant $72 \%$ ). The most common site of distant metastases was the brain, particularly in nonsquamous lung cancers. Local or regional recurrence was slightly more common in patients with squamous carcinoma 


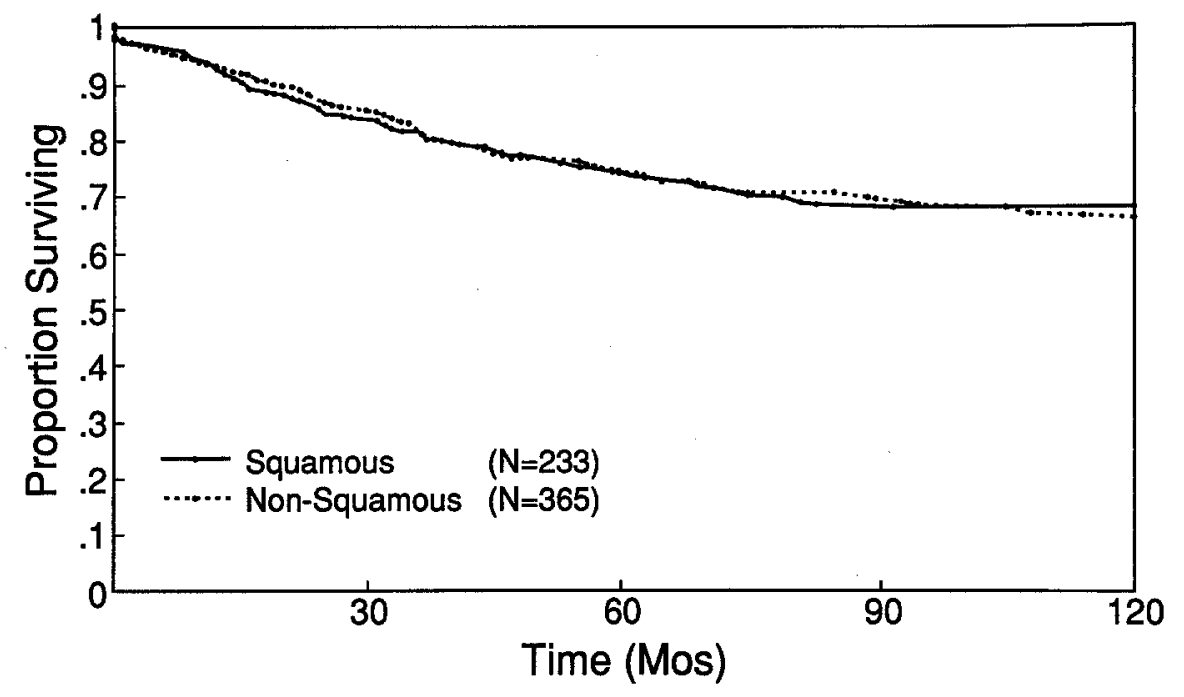

Fig. 5. Survival by histologic type.

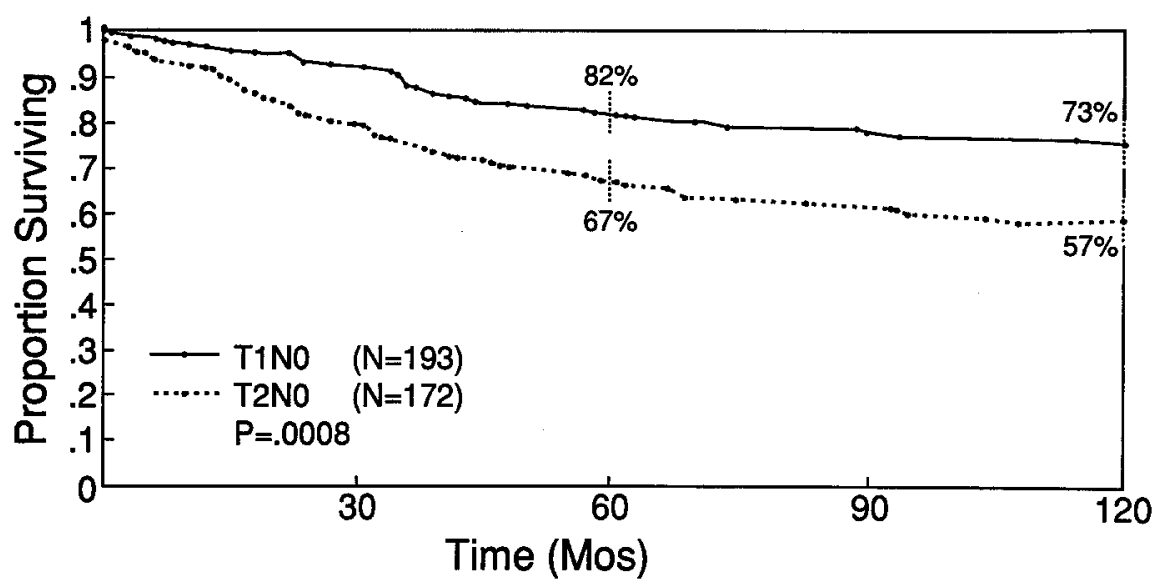

Fig. 6. Survival by $\mathrm{T}$ factor in resected stage I nonsquamous cancers.

Table IV. Frequency of recurrences from initial treatment by year of follow-up

\begin{tabular}{crr}
\hline $\begin{array}{c}\text { Years after } \\
\text { resection }\end{array}$ & No. & $\%$ \\
\hline 1 & 55 & 35 \\
2 & 39 & 25 \\
3 & 27 & 17 \\
4 & 16 & 10 \\
5 & 7 & 4 \\
$>5$ & 15 & 9 \\
Total & $\underline{159}$ & 100 \\
\hline
\end{tabular}

as compared with those with nonsquamous lung cancers (32\% versus $26 \%$ ).

Lesser resections than lobectomy and no lymph node dissection had adverse effects on recurrence and survival. Despite a complete resection, 31 of 62 patients $(50 \%)$ who had wedge resection or segmentectomy had recurrence $(p=0.00002), 14$ of whom had local or regional recurrences. Twenty-one of 38 $(55 \%)$ patients who had no lymph node dissection had recurrence $(p=0.00008), 18$ of whom had local or regional recurrences $(71 \%)$. Only $5 \%$ of all recurrences were local or regional recurrence in patients who had mediastinal lymph node dissection. The 5- and 10-year survivals after wedge resection or segmentectomy were $59 \%$ and $35 \%(p=$ $0.026)$; the 5 - and 10 -year survivals in those who had no lymph node dissection were 59\% and $32 \%(p<$ 0.0005).

The incidence of recurrence was influenced by the $\mathrm{T}$ factor and by tumor size in centimeters. The 
Table V. Sites of first recurrence in 159 patients

\begin{tabular}{|c|c|c|c|}
\hline \multirow[b]{2}{*}{ Sites of recurrence } & All patients & Squamous Ca & Nonsquamous $\mathrm{Ca}$ \\
\hline & First site (anytime) & First site (anytime) & First site (anytime) \\
\hline Local & 32 & 12 & 20 \\
\hline Stump & 5 & 1 & 4 \\
\hline Lung & $27^{*}$ & 11 & 16 \\
\hline Regional (N2-N3) & 13 & 6 & 7 \\
\hline Distant & 109 & 38 & 71 \\
\hline Brain & $51(54)$ & $13(13)$ & $38(41)$ \\
\hline Lung & $20(29)$ & $7(9)$ & $13(20)$ \\
\hline Liver & $14(18)$ & $11(12)$ & $3(6)$ \\
\hline Bone & $11(24)$ & $3(5)$ & $8(19)$ \\
\hline Other & 8 & 3 & 5 \\
\hline Disseminated & 5 & 1 & 4 \\
\hline Local + distant & 3 & 1 & 2 \\
\hline Regional + distant & 2 & - & 2 \\
\hline Total & $\overline{159}$ & $\overline{57}$ & $\overline{102}$ \\
\hline
\end{tabular}

*Twenty-one of 27 treated by wedge resection or segmentectomy.

difference was statistically significant between T1 and T2 tumors $(p=0.0004)$, between tumors $3 \mathrm{~cm}$ or smaller and those greater than $3 \mathrm{~cm}$ but equal to or less than $5 \mathrm{~cm}(p=0.03)$, and between tumors larger than $3 \mathrm{~cm}$ to $5 \mathrm{~cm}$ and those greater than $5 \mathrm{~cm}$ $(p=0.03)$.

Multiple primary cancers. A total of 206 patients had second cancers, an overall incidence of $34 \%$. This incidence was similar between histologic types (squamous carcinoma 32\%, nonsquamous cancer $36 \%$ ). The second primary tumors were synchronous in 24 and metachronous in 182 patients (Table VI). One third of the multiple cancers were lung cancers. A total of 69 patients had two primary lung cancers, 14 of which were synchronous and 55 metachronous ( 10 before, 45 after). Fifteen patients had a third cancer, five of whom had triple lung cancers, four from the metachronous group and one from the synchronous group.

Late recurrences and new cancers. In our series, 391 patients with resected stage I non-small-cell lung cancer lived 5 or more years (204 T1 N0 and 187 T2 N0). Fifteen recurrences occurred after 5 years. Two of these were local recurrences: One patient who had a wedge resection was treated by completion lobectomy and remains alive and disease-free 10 years later. Another had a local recurrence 7 years after a lobectomy and sleeve resection and was treated by radiation. He also remains alive and well at $81 / 2$ years. Of the remainder, eleven died of their disease, one is alive and well after resection of a brain metastasis, and one is alive and well after resection of a rib metastasis. In addition, new cancers developed 5 or more years after treatment of
Table VI. Incidence of multiple cancers in 598 patients*

\begin{tabular}{lrrrr}
\hline \multicolumn{1}{c}{ Site } & Before & Simultaneous & After & Total \\
\hline Lung & 10 & 14 & 45 & $69(33 \%)$ \\
Breast & 25 & 3 & 6 & 34 \\
Head and neck & 21 & 1 & 4 & 26 \\
Colon/rectum & 8 & - & 8 & 16 \\
Bladder & 8 & 1 & 5 & 14 \\
Cervix/uterus & 6 & 3 & 1 & 10 \\
Prostate & 3 & - & 3 & 6 \\
Ovary & 1 & - & - & 1 \\
Esophagus & - & - & 3 & 3 \\
Stomach & - & - & 3 & 3 \\
Pancreas & - & - & 6 & 6 \\
Kidney & - & - & 3 & 3 \\
Melanoma & 6 & 1 & - & 7 \\
Hodgkin's & 1 & - & - & 1 \\
Lymphoma & - & 1 & - & 1 \\
Myeloma & - & - & 3 & 3 \\
Leukemia & 1 & - & - & 1 \\
Thymoma & 1 & - & - & 1 \\
Sarcoma & 1 & $\overline{\overline{24}}$ & $\overline{90}$ & $\frac{1}{206}$ \\
Total & $\overline{92}$ & &
\end{tabular}

*A third cancer developed in patients from this group-eight cancers of the lung, two of the larynx, and one each of the colon, prostate, skin (melanoma), and bone (multiple myeloma).

the initial lung cancer in 35 patients. Twenty of them were new lung cancers (Table VII).

To date, 279 patients are alive and well 5 to 19 years after treatment with a median follow-up of 119 months. Seven additional patients were lost to follow-up 18 to 55 months after treatment (median follow-up, 36 months). Sixteen are alive with disease at $3 \frac{1}{2}$ to 16 years after treatment (median follow-up, 91 months). There were 289 late deaths, 113 of 
Table VII. Incidence of recurrence and new cancers in patients alive and well after 5 or more years

\begin{tabular}{|c|c|c|c|c|c|c|}
\hline & \multicolumn{2}{|c|}{ T1 NO } & $T 2 N O$ & \multicolumn{3}{|c|}{$\begin{array}{c}\text { All stage } \\
I\end{array}$} \\
\hline Alive and well & & 204 & & 187 & & 391 \\
\hline Recurrence & & 8 & & 7 & & 15 \\
\hline Local & & 2 & & 1 & & 3 \\
\hline Stump & 1 & & - & & 1 & \\
\hline Lung & 1 & & 1 & & 2 & \\
\hline Regional (N2) & & - & & 1 & & 1 \\
\hline Distant & & 6 & & 5 & & 11 \\
\hline Brain & 2 & & 3 & & 5 & \\
\hline Lung & 1 & & 1 & & 2 & \\
\hline Liver & - & & 1 & & 1 & \\
\hline Bone + lung & 1 & & - & & 1 & \\
\hline Brain + bone & 1 & & 一 & & 1 & \\
\hline Bone & 1 & & - & & 1 & \\
\hline New cancers & & 20 & & 15 & & 35 \\
\hline Lung & 13 & & 7 & & 20 & \\
\hline Bladder & 1 & & 2 & & 3 & \\
\hline Colon/rectum & 1 & & 2 & & 3 & \\
\hline Breast & 2 & & - & & 2 & \\
\hline Tongue & - & & 1 & & 1 & \\
\hline Pharynx & - & & 1 & & 1 & \\
\hline Stomach & 1 & & - & & 1 & \\
\hline Pancreas & 1 & & 一 & & 1 & \\
\hline Uterus & - & & 1 & & 1 & \\
\hline Kidney & 1 & & - & & 1 & \\
\hline Prostate & - & & 1 & & 1 & \\
\hline
\end{tabular}

unrelated causes and 176 either of the original or subsequent lung cancer. Deaths from unrelated causes were due to a new cancer other than lung in 25 , cardiorespiratory problems in 51 (myocardial infarction, chronic obstructive pulmonary disease, pneumonia, pulmonary embolism, or stroke), hepatic failure caused by cirrhosis in 4 , suicide in 3 , and natural causes while free of cancer in 30 .

\section{Discussion}

Few lung cancers are potentially curable. For those patients with stage I non-small-cell carcinoma, however, surgical resection offers a significant chance of cure. ${ }^{10-16}$ Radiographically occult carcinomas of the lung detected on sputum cytologic examination represent a very small group of lung cancers, but early removal of these tumors after localization results in cancer cure in the vast majority.

In 1977 , we ${ }^{17}$ reported our preliminary survival results with the surgical treatment of stage I lung cancer and demonstrated favorable results with complete resection combined with mediastinal lymph node dissection. By 1983, follow-up data were available for at least 5 years on 136 patients treated by lobectomy or pneumonectomy. ${ }^{12}$ The 5 -year sur- vival was $83 \%$ for patients with T1 tumors and $65 \%$ for those with $\mathrm{T} 2$ tumors, with an overall 5-year survival of $72 \%$. No local recurrence was observed in this group of patients and only three had regional lymph node metastases, emphasizing the need for a complete lymph node dissection to ensure the absence of nodal metastasis and also emphasizing the need to do a lobectomy in patients with stage I lung cancer regardless of the small size of the tumor or its peripheral position.

In our early experience, we had not found vascular or lymphatic invasion or grading to have prognostic significance. As a result, these parameters were not routinely recorded in our pathology reports. Although our current reporting is more standardized and these observations are now noted, we attempted to address grading by reviewing 200 randomly selected cases from our series and found that grading had no predictive value on survival in these patients who had complete resections.

Vascular or lymphatic invasion as a predictor of survival has been controversial. The Veterans Administration Surgical Oncology Study Group had reviewed 865 resections for lung cancer, and the presence or absence of lymphatic or blood vessel invasion was recorded in $90 \%$ of the cases. ${ }^{8}$ Blood vessel invasion was found to have no predictive value, but lymphatic invasion did in patients with squamous cell cancers. In a more recent publication, blood vessel invasion was reported to be a main predictor of recurrence in T1 N0 M0 disease nonsmall-cell lung cancer. ${ }^{4}$ Of 95 patients treated by resection, 16 had blood vessel invasion and all have died of their cancer. However, the distinction between blood vessel and lymphatics is not always possible even with the use of special stains.

The value of flow cytometry to assess the deoxyribonucleic acid content has also been controversial. ${ }^{18}$ Although reports have noted that deoxyribonucleic acid assessment is valuable, ${ }^{5,9}$ this was not prognostic in our experience ${ }^{19}$ or in that of the Lung Cancer Study Group. ${ }^{3}$

A similar controversy exists between advocates of elective segmentectomy or wedge resection ${ }^{20}$ and those who recommend a lobectomy as the procedure of choice. In one series, patients with wedge resection did better than those treated by lobectomy or pneumonectomy because median tumor size was smaller. ${ }^{4}$ In another series, patients with tumors less than $2 \mathrm{~cm}$ in diameter within the T1 N0 group had a survival advantage. ${ }^{21}$ It was concluded that deepseated lesions necessitate a lobectomy, but lesser 
resections are justified in patients with peripheral tumors less than $2 \mathrm{~cm}$ in diameter, because they do better and perhaps should be analyzed separately. These two reports contradict the observations made by the Lung Cancer Study Group ${ }^{22}$ and by our current series. Our experience confirms that any resection less extensive than lobectomy places the patient at an increased risk of local recurrence and decreases the chances of long-term survival. Only in those patients with compromised cardiopulmonary function do we recommend a conservative resection such as segmentectomy or wedge resection.

Regardless of the extent of pulmonary resection, systematic mediastinal lymph node dissection should be routinely performed to stage the disease accurately by ascertaining that lymphatic metastases are absent.

Recurrence after initial treatment was identified by radiographic or laboratory evidence and whenever possible by pathologic confirmation. Local and regional recurrences are the result of inadequate initial excision and are considered to represent persistent disease, not a second carcinoma. Recurrences at any site are most commonly detected within the first 2 years after treatment and diminish in occurrence with time. However, inasmuch as these patients live long and overcome their first carcinoma, they remain at risk for second carcinomas. When a complete, potentially curative resection of a primary carcinoma of the lung is performed, when the margins are clear, and when lymph node metastasis is absent, any new lesion, even if in the same lung, may well represent a new and separate primary tumor. Guidelines for acceptance of a carcinoma as a new and separate lung carcinoma were reported by us $^{23}$ and are shown in Table I. The diagnosis is most convincing when the new lesion is in the contralateral lung and the histologic type of the new tumor is different.

The Lung Cancer Study Group had stated that cancer recurrence represents treatment failure whereas development of new cancers suggests persistent exposure to etiologic risk factors. ${ }^{24}$ We concur with this explanation and agree with the need for continued surveillance beyond 5 years. The frequency with which second primary tumors are detected in this group of patients is high and poses a threat to survival despite the potentially curative resection of the initial primary lung cancer.

The emphasis on 5-year survival may be misleading in patients with treated cancers with low recurrence rates. In resected stage I non-small-cell lung cancer, a significant proportion of patients die of other causes and free of cancer. In our series, the incidence of deaths from unrelated causes was $19 \%$. In many studies, patients with prior head and neck, lung, and breast cancers have been excluded, as well as patients with prior cancers treated within 5 years. $^{24,25}$ In our series, inclusion of previously treated cancers including head and neck cancers did not adversely affect survival.

The high frequency of the development of second primary lung cancers was also noted in our early report on 136 patients treated by resection for stage I lung cancer (32\% second cancers, $34 \%$ of which were second primary lung cancers). Our current review notes the same high frequency, namely, a $34 \%$ incidence of second cancers, a third of which are second lung cancers.

Because vitamin A and retinoids were found to be strong inhibitors of epithelial cancer progression in experimental carcinogenesis, several randomized studies are currently in progress to assess the merits of retinoids in improving the disease-free interval by preventing secondary aerodigestive cancers or recurrence in patients cured of an early lung cancer. $^{26,27}$ The data are still viewed as preliminary and will require several years of follow-up before definitive conclusions can be drawn. At this time, it is recommended that retinoids and vitamin $\mathrm{A}$ be offered only in protocol settings.

\section{Summary and conclusions}

1. Pathologic stage I lung cancer is early cancer and is best treated surgically.

2. Lobectomy is the procedure of choice even if the tumor is small and peripheral. Wedge resection or segmentectomy should be limited to patients with prior pulmonary resections, poor pulmonary reserve, or other major medical problems that preclude a safe lobectomy.

3. The mediastinal evaluation must be thorough to ensure that the patient has early stage I disease. Computed tomographic scans help in identifying enlarged mediastinal lymph nodes. Whether one chooses to do a mediastinoscopy or proceed directly to a thoracotomy, a systematic nodal evaluation, preferably by dissection of all accessible nodes, will ensure that no nodal disease is present and the favorable prognostication will be more accurate.

4. Histologic type and visceral pleural invasion per se are not prognostic, but the extent of the disease and its resectability are prognostic and affect survival.

5. Tumor size is important. The smaller the primary tumor, the better the prognosis. Tumors de- 
tected when less than $1 \mathrm{~cm}$ in diameter do best, and tumors greater than $5 \mathrm{~cm}$ do poorest.

6. Recurrences do occur, despite early-stage disease, mostly in the first 2 years, but nearly $10 \%$ develop 5 or more years after treatment.

7. Because these patients live long and overcome their first cancer, they are at risk for second cancers. Therefore, an indefinite period of surveillance well beyond 5 years is necessary.

We gratefully acknowledge Phyllis Byczek for her assistance in collating the data and her tireless efforts in obtaining status follow-up on all patients.

\section{REFERENCES}

1. Gail MH, Eagan RT, Feld R, et al. Prognostic factors in patients with resected stage I non-small cell lung cancer: a report from the Lung Cancer Study Group. Cancer 1984;54:1802-13.

2. Martini N, Ghosh P, Melamed MR. Local recurrence and new primary carcinoma after resection. In: Delarue $\mathrm{NC}$, Eschapasse $\mathrm{H}$, eds. International trends in general thoracic surgery. Vol 1. Philadelphia: WB Saunders, 1985:164-9.

3. Thomas $P$, Rubinstein L, Lung Cancer Study Group. Cancer recurrence after resection: T1 N0 non-small cell lung cancer. Ann Thorac Surg 1990;49:242-7.

4. Macchiarini P, Fontanini G, Hardin MJ, et al. Blood vessel invasion by tumor cells predicts recurrence in completely resected T1 N0 M0 non-small-cell lung cancer. J Thorac Cardiovasc Surg 1993;106:80-9.

5. Shimizu N, Ando A, Date H, Teramoto S. Prognosis of undetected intrapulmonary metastases in resected lung cancer. Cancer 1993;71:3868-72.

6. Deslauriers J, Brisson J, Cartier R, et al. Carcinoma of the lung: evaluation of satellite nodules as a factor influencing prognosis after resection. J THORAC CARDIOVASC SURG 1989;97:504-12.

7. Rice TW, Bauer TW, Gephardt GN, Medendorp SV, McLain DA, Kirby TJ. Prognostic significance of flow cytometry in non-small-cell lung cancer. J THORAC CARDIOVASC SURG 1993;106:210-7.

8. Shields TW. Prognostic significance of parenchymal lymphatic vessel and blood vessel invasion in carcinoma of the lung. Surg Gynecol Obstet 1983;157:18590.

9. Volm M, Hahn EW, Mattern J, Muller T, VogtMoykopf I, Weber E. Five-year follow-up study of independent clinical and flow cytometric prognostic factors for the survival or patients with non-small cell lung carcinoma. Cancer Res 1988;48:2923-8.

10. Flehinger BJ, Kimmel M, Melamed MR. The effect of surgical treatment on survival from early lung cancer: implications for screening. Chest 1992;101:1013-8.

11. Ichinose $\mathrm{Y}$, Hara $\mathrm{N}$, Ohta $\mathrm{M}$, et al. Is $\mathrm{T}$ factor of the
TNM staging system a predominant prognostic factor in pathologic stage I non-small-cell lung cancer? A multivariate prognostic factor analysis of 151 patients. J THORAC CARDIOvasC SuRg 1993;106:90-4.

12. Martini N, McCaughan BC, McCormack PM, Bains MS. The extent of resection for localized lung cancer: Lobectomy. In: Kittle CF, ed. Current controversies in thoracic surgery. Philadelphia: WB Saunders, 1986: 171-4.

13. Martini N, Zaman MB, Melamed MR. Early diagnosis in carcinoma of the lung. In: Roth JA, Ruckdeschel JC, Weisenburg TH, eds. Philadelphia: WB Saunders, 1989:133-41.

14. Melamed MR, Flehinger BJ, Zaman MB, Heelan RT, Hallerman ET, Martini N. Detection of true pathologic stage I lung cancer in a screening program and the effect on survival. Cancer 1981;47:1182-7.

15. Mountain CF, Gail MH. Surgical adjuvant intrapleural BCG treatment for stage I non-small cell lung cancer: preliminary report of the National Cancer Institute Lung Cancer Study Group. J THORAC CARDIOVASC SURG 1981;82:649-57.

16. Moores DWO, McKneally M. Treatment of stage I lung cancer (T1N0M0, T2NOM0). Surg Clin North Amer 1987;57:5:937-43.

17. Martini N, Beattie EJ. Results of surgical treatment in stage I lung cancer. J Thorac Cardiovasc Surg 1977;74:499-505.

18. Schmidt RA, Rusch VW, Piantadosi S. A flow cytometric study of non-small cell lung cancer classified as T1N0. Cancer 1992;69:78-85.

19. Cibas ES, Melamed MR, Zaman MB, Kimmel M. The effect of tumor size and tumor cell DNA content on the survival of patients with stage I adenocarcinoma of the lung. Cancer 1989;63:1552-6.

20. Jensik RJ. The extent of resection for localized lung cancer: segmental resection. In: Kittle CF, ed. Current controversies in thoracic surgery. Philadelphia: WB Saunders, 1986:175-82.

21. Read RC, Yoder G, Schaeffer RC. Survival after conservative resection for T1 N0 M0 non-small cell lung cancer. Ann Thorac Surg 1990;49:391-400.

22. Ginsberg RJ for the Lung Cancer Study Group. Limited resection for peripheral T1N0 tumors. Lung Cancer Supplement, 1988;4:A80.

23. Martini N, Melamed MR. Multiple primary lung cancers. J THORAC CARDIOVASC SuRG 1975;70:606-12.

24. The Lung Cancer Study Group, Prepared by Thomas PA Jr, Rubinstein L. Malignant disease appearing late after operation for T1 N0 non-small-cell lung cancer. J Thorac Cardiovasc Surg 1993;106:1053-8.

25. Massard G, Roeslin N, Jung G-M, Dumont P, Wihlm $\mathrm{J}-\mathrm{M}$, Morand G. Bronchogenic cancer associated with head and neck tumors: survival analysis of 194 patients. J Thorac Cardiovasc SuRg 1993;106:218-27.

26. Pastorino U, Infante M, Maioli M, et al. Adjuvant 
treatment of stage I lung cancer with high-dose vita$\min$ A. J Clin Oncol 1993;11:1216-22.

27. Lippman SC, Hong WK. Not yet standard: retinoids versus second primary tumors (Editorial). J Clin Oncol 1993;11:1204-7.

\section{Discussion}

Dr. L. Penfield Faber (Chicago, Ill.). Dr. Martini and the group from Memorial have established another "gold standard" for the surgical treatment of non-small-cell lung cancer. The earlier report by Drs. Martini and Beattie recommended lobectomy as the resection of choice for stage I lung cancer. The projected survival at 5 years for patients with T1 N0 disease after lobectomy was approximately $80 \%$. To me, a gold standard procedure is one to which other variations of resection are compared. Those of us who are reporting results of segmental resections, wedge resections, or resections by video-assisted thoracic surgical techniques must document similar results if these procedures are to become accepted as standard. This exquisitely defined study with exquisitely defined lymph node resection and surgical/pathologic staging sets the standard. It also provides patients with stage I disease a degree of optimism.

I agree that it is important to accomplish a complete lymphadenectomy to assure that these are stage I lesions. I concur with Dr. Martini that lymphadenectomy is important for staging and also achieves a more complete resection with an enhanced cure rate.

Dr. Martini, how do you define and differentiate local recurrence from a second primary. A review of the literature of lung cancer shows that second primaries have various definitions, such as the second tumor appearing more than 2 years after the initial resection or the tumor arising in another lobe, having a contralateral location, and being of a different histologic type. Definitions for a second primary do vary, and it can be troublesome to differentiate the development of a second primary from locoregional recurrence.

My second question concerns the recommended approach to solitary metastatic disease in organs other than the brain. What should be done about resection of solitary metastatic tumors in other organs that would include the adrenal gland, the contralateral lung, and the liver?

Dr. Martini. We define local recurrence as disease found in lung in patients who had a lesser resection than a lobectomy or disease found at the bronchial resection margin after a lobectomy or pneumonectomy. We define regional recurrence as development of N2 or N3 disease despite a careful mediastinal lymph node evaluation at the initial operation. All other sites of recurrence are referred to as distant recurrence.

The diagnosis of a new primary tumor is most convincing when the histologic type of the new tumor is different. Also accepted as a new primary is a new lesion in the contralateral lung or different lobe with no carcinoma in lymphatics common to both. We have also accepted as multiple lung primaries, squamous carcinomas in the same lobe when we have clearly identified the origin of each from a carcinoma in situ.

The best treatment for a solitary distant metastasis after adequate control of a primary tumor presumed to be stage I is still an unresolved question. In our opinion, if the solitary area of metastasis is resectable, it should be resected, just as we have done with solitary brain metastasis. We do not have the same experience with the adrenal gland. We have on occasion resected solitary skin metastases or rib metastases with a resultant prolonged survival.

It is important to remember that the treatment for a patient with a solitary lung lesion, be it metastatic or a new primary, ought to be surgical with expectations of prolonged survival.

Dr. John R. Benfield (Sacramento, Calif.). An important part of your presentation has been that patients who have had lesser resections and lesser lymph node dissections have fared less well than those who have had the more extensive procedures.

Because this was a retrospective study, I am curious to know what selection criteria were used for the patients who had these lesser resections. Is it possible that the lesser survivals among those patients were, at least in part, the result of factors other than the operations that were done?

Dr. Martini. We were heavily influenced from the outset by the fact that the surgical treatment of patients with lung cancer, however small or early, should be no less than a lobectomy. We offered lesser resections only to patients with limited cardiopulmonary reserve caused by chronic obstructive pulmonary disease or prior pulmonary resection for lung cancer and, at times, after a mistaken frozen section diagnosis of metastasis or benign disease. When we did that, we noted a local recurrence rate of $19 \%$. The largest series in this country comes from Rush-Presbyterian-St. Luke's Medical Center reported by Jensik, Faber, Kittle and Warren. In this series elective segmentectomies have resulted in a $12 \%$ to $15 \%$ incidence of local recurrence.

Because of this fact, we believe very strongly that in a patient with adequate lung reserve who has early lung cancer, there is no justification to do a miniresection and risk local recurrence.

Dr. Donald L. Morton (Santa Monica, Calif.). What pathologic criteria did you use to determine the absence of lymph node metastases? We recently reviewed a series of patients with lung cancer whose mediastinal nodes had no evidence of metastases by standard histopathologic examination with hematoxylin and eosin stains. However, more sensitive immunohistochemical stains revealed micrometastases in $30 \%$ of the dissection specimens. I am therefore intrigued by your $30 \%$ rate of recurrence in patients without nodal metastases. I put forth the hypothesis that most patients with recurrence have regional node micrometastases that are too small to be detected by routine hematoxylin and eosin staining.

Dr. Nael Martini. Dr. Morton, this is a very interesting piece of information. Our only method of determining that a patient has no regional lymph node metastasis has been the meticulous histologic light microscopic review of any lymph nodes we submitted. Because we were doing lymph node dissections, the approximate number of lymph nodes submitted from the mediastinum varied from 25 to 40 . Admittedly, many intraparenchymal and segmental nodes may be overlooked if step sectioning is not done. 